\title{
Assessment of Different Parking Pricing Strategies: A Simulation-based Analysis
}

\author{
Zhenyu Mei ${ }^{1} \mathbb{D}$, Chi Feng ${ }^{1}$, Liang Kong ${ }^{1}$, Lihui Zhang ${ }^{1, *}$ and Jun Chen ${ }^{2}$ \\ 1 College of Civil Engineering and Architecture, Zhejiang University, Hangzhou 310058, China; \\ meizhenyu@zju.edu.cn (Z.M.); 21712090@zju.edu.cn (C.F.); 3150100337@zju.edu.cn (L.K.) \\ 2 School of Transportation, Southeast University, Nanjin 210096, China; chenjun@seu.edu.cn \\ * Correspondence: lihuizhang@zju.edu.cn
}

Received: 9 January 2020; Accepted: 2 March 2020; Published: 7 March 2020

check for updates

\begin{abstract}
Parking demand exceeding parking supply and uneven parking demand distribution are the existing conflicts in city centers. Parking pricing is frequently utilized to manage parking resources. This study aims to assess different parking pricing strategies through simulations for providing operational suggestions for urban parking managers. Two widely used parking pricing strategies in China combined with an optimized parking pricing strategy are proposed and compared. We introduce an agent-based simulation system to describe the parking and traffic conditions. Various measures of effectiveness under different parking pricing strategies can be obtained via agent-based simulations. We then construct a comprehensive benefit combining average cost and failure rate. Results show that the second strategy with charging different parking fees by considering locations and third optimized strategy can effectively improve traffic efficiency. However, the second strategy may lead to higher average cost than that of the third one. Thus, the third optimized strategy performs the best and can be used to optimize the parking policy of parking managers in the future. The entire assessment through simulations can provide evaluation suggestions for parking managers to adjust parking policies.
\end{abstract}

Keywords: parking pricing; optimized strategy; agent-based simulation; assessment

\section{Introduction}

Many cities encounter parking problems with rapid urbanization and increase in the number of vehicles. The parking demand in city centers frequently exceeds the supply, and parking spaces are usually distributed unevenly, leading to overcrowding of popular parking lots [1]. Drivers need to compete for limited popular parking spaces, and those losing ones will have to cruise around, thereby increasing the travel time and is inconvenient for drivers. On the one hand, government agencies may consider building additional parking lots to address this current dilemma. However, this task is difficult to implement and sustain because of the limitations in capital and land resources [2]. On the other hand, many parking management instruments are acknowledged to mitigate parking problems, in which parking pricing is an effective strategy. Parking pricing may change drivers' parking choices and lead to improved parking distribution and resource utilization.

Parking pricing has elicited extensive attention in the literature. Related research is divided into two categories, namely, the impact of parking price rates on parking demand and the study of parking charging methods. The first category of research focuses on the sensitivity of users to parking charges. Wilson (1992) used a multinomial logit model to assess the effects of employer-paid parking on the mode choice and parking demand of downtown Los Angeles commuters. Thresholds of parking fare increase are found to change an already chosen parking location or to shift to another mode from private cars [3]. Tsamboulas (2001) presented a logit model and analyzed the parking fare thresholds to 
estimate the changes in car usage and parking location utilization [4]. Kelly and Clinch (2006) analyzed a survey on 1007 on-street parkers in Dublin, Ireland, and found a progressively widening gap in price sensitivity between trips made for business and nonbusiness purposes [5]. Public acceptance of increased parking fare is an important issue. Bonsall and Young (2010) developed a charge strategy based on public acceptance. Their analysis suggested that the combined effect might be beneficial to the local economy and yield a net increase in revenue although the removal of parking charges would reduce revenues [6]. Jansson (2010) believed that the taxation of the free or highly subsidized parking provided by employers in city centers could be extremely useful for alleviating urban congestion [7]. The second category of research focuses on the impact of parking charging methods on parking behavior. Caicedo (2011) analyzed the parking charge in terms of minutes to obtain its impact on parking turnover and revenues [8]. Zhang and Zhu (2016) introduced a critical value of user-acceptable parking fee into a parking choice model and analyzed the influence of parking fee on drivers' parking choice and roadside parking utilization [9]. Dale et al. (2017) assessed the impact of workplace parking tax on local traffic congestion in Nottingham and found that traffic congestion is immensely alleviated by the said tax [10]. Gao et al. (2018) proposed a price-based tradable credit scheme to minimize social costs by optimizing the credit scheme and the number and location of parking and transfer stations [11]. Cai et al. (2018) proposed a parking space allocation method based on open window, parking fee, and reservation ratio to improve the utilization of the appertaining parking lots of public buildings [12]. Hao et al. (2019) proposed a dynamic balance adjustment method for shared parking mode, and the research results showed that the floating charge method can improve the utilization rate of idle spaces by more than $60 \%$ compared with fixed fees [13].

In addition to the research of parking price, parking reservation systems (PRSs) have been rapidly developed with the development of information and mobile Internet technologies. The original intention of the PRS concept in the field of intelligent transportation is to assure users with parking space and avoid scrambling for parking spaces by making an advance reservation [14]. PRS reduces traffic congestion, optimizes the utilization of parking resources, maximizes parking revenue, and reduces user time consumption. Therefore, PRS is preferred as a new method to alleviate urban parking problems $[15,16]$. The reservation of some parking spaces is allowed in the reservation system $[17,18]$. With these advantages, parking reservations are considered in the parking pricing strategy.

The existing research provides the price design and charging methods but explicitly ignores the different parking pricing strategies, especially on parking reservations. Consequently, parking pricing strategies should be assessed and optimized in terms of average cost and failure rate.

This paper proposes two currently used charging strategies and an optimized parking strategy. This optimized strategy is proposed for different charging prices by comprehensively considering different locations, time periods, and methods. Different parking lots may charge different prices, parking prices may vary at different time periods, and parking reservation fees differ for parking reservations. This analysis is still lacking in the literature.

Drivers' individual parking behavior, such as cruising for available spaces, needs to be captured in detail to assess different parking pricing strategies. Parking behavior is affected by various factors, such as the characteristics of drivers, road conditions, and traffic conditions. Establishing a mathematical model that describes all types of individual behavior is difficult. Thus, other approaches have been proposed. Caliskan et al. (2007) built a continuous-time homogeneous Markov parking model based on queuing theory to simulate vehicular ad hoc networks [19]. Klappenecker et al. (2010) provided mathematical proof of the expected time for a vehicle to leave a parking lot. However, several parameters of these models, such as departure and arrival rates, do not conform to practical applications. Many recent studies have achieved progress in the use of agent technology for building intelligent transportation systems, including parking guidance information systems and PRSs [20]. Chou et al. (2008) proposed a dynamic parking negotiation and guidance algorithm through an agent-based platform [21]. Sun et al. (2015) modeled drivers' responses to parking variable message signs under various parking information through agent-based simulation [22]. Boudali and Ouada 
(2017) proposed a smart parking system based on multiagent approach to provide real-time decision aid for drivers considering their preferences [23]. Tasseron and Martens (2017) evaluated the influences of different proportions of reservation users through agent simulation [16]. Mei et al. $(2019,2020)$ constructed an agent simulation framework to compare parking pricing and parking reservation and optimize parking space configuration [17,18].

These studies have shown that agent-based simulation can effectively describe the dynamic movement, decision making, and self-organizing of traffic networks, and can be simulated and evaluated for actual scenarios. Therefore, this study also establishes an agent-based simulation model, and applied it in a typical area of Wulin CBD, Hangzhou, China to support the evaluation and optimization of different parking pricing strategies.

The remainder of this paper is structured as follows: Section 2 presents the parking pricing strategies to be analyzed and research methods. Section 3 introduces the agent-based simulation model to describe parking and traffic conditions. Section 4 illustrates the evaluation of different parking pricing strategies using the Wulin Business Center in Hangzhou City as a case study. Section 5 provides the conclusions and recommendations for future work.

\section{Parking Pricing Strategies and Research Methods}

\subsection{Parking Pricing Strategies}

Pricing is a typical market-oriented instrument that distributes resources to users with high willingness to pay (users with high demand to a certain extent) through price adjustment. It has been widely used in various domains, such as food and commercial housing, and is proven to be useful. In this section, we will present the three parking pricing strategies.

The widely used parking pricing strategy in China is where different parking lots constantly charge the same price, which is the first strategy. However, parking demand exceeding parking supply and uneven parking demand distribution lead to the overcrowding of popular parking lots. With the increasingly serious parking issues, some government agencies consider to allocate parking resources by charging different parking fees [24], which is the second strategy. Comprehensively considering different locations, time periods, and methods, we propose different parking fees during peak periods, which is the third strategy. Thus, the three pricing strategies are defined as follows:

Different parking lots constantly charge the same price: all parking lots charge the same parking (for all users) and same reservation fees (for reserved users);

Different parking lots constantly charge different prices: parking lots can have different parking (for all users) and different reservation fees (for reserved users);

Different parking lots charge different prices during peak periods: we set two space occupancy percentage (SOP) thresholds, namely, large and small thresholds. When a parking lot's SOP is higher than the large threshold, it will enter into its peak period. When its SOP gets lower than the small threshold, its peak period will finish. Only during its own peak period, it can have different parking and reservation fee.

\subsection{Research Methods}

Parking pricing strategies are proposed above, so the next thing is assessment. We adopt the following research methods:

1. Build an agent-based simulation model to describe parking and traffic conditions;

2. Simulate the three proposed parking pricing strategies in the model separately;

3. Find the best performance strategy by comparing simulation results. 


\section{Agent-based Simulation Model}

\subsection{Agent Types}

The simulation system mainly includes vehicles, road network, and parking lots. Thus, vehicle, road, and parking lot agents need to be introduced.

A vehicle agent describes the driver's operation in the road network, the decision making at each decision point, and the process and result of searching for a parking lot. At road intersections, the vehicle agent needs to decide its driving path in accordance with the location of its target parking lot and the current network traffic condition.

A road agent describes the traffic volume, travel speed, and travel time of each section in the road network at each time step and influences the path selection of the vehicle agent.

A parking lot agent describes the actual parking and queuing statuses at each time step.

\subsection{Basic Assumptions}

The simulations in this study are based on the following assumptions.

- $\quad$ The road network and OD (ORINGIN and DESTINATION) travel demand are fixed.

- All parking lots are off-road public parking lots.

- All users can obtain favorable traffic information and travel with minimum costs.

- Real-time information of all parking spaces in the intelligent PRS is available.

- Reserved users constantly use the reserved parking space to accomplish parking.

- The proportion of reserved parking spaces is fixed.

- Users who cannot successfully reserve an empty parking space are considered non-reserved users.

\subsection{Agent-based Simulation Flowchart}

The flowchart of the proposed agent-based simulation model is shown in Figure 1. It describes the entire process of vehicles traveling from the origins to their parking lots. Vehicles are divided into two categories, namely, non-reserved and reserved vehicles. Their differences in decision making are illustrated in Figure 1.

Several major steps are summarized as follows:

\section{Model Initialization}

For the road network, the road grade (arterial/sub-arterial road), road capacity, free-flow speed, preloaded traffic flow, travel time calculated by the Bureau of Public Roads (BPR) function, and travel speed need to be initialized. For parking lots, the parking capacity, initial occupation, and maximum tolerable queuing length need to be initialized. For the simulation environment, the simulation interval, current number of iterations, maximum number of iterations $M$, total simulation $\mathrm{OD}$, and proportion of reserved users are initialized.

2. Vehicle Departure and Queuing Sequence Update

A certain number of vehicles accomplish parking and leave, following a Poisson distribution. Vehicles waiting in queues will acquire their parking spaces on a first-come-first-served basis. Then, the SOP of each parking lot is updated as follows:

$$
o_{j}^{m}=\frac{q_{j}^{m}}{C_{j}}
$$

where $o_{j}^{m}$ is the SOP of parking lot $j$ at iteration $m, q_{j}^{m}$ is the number of parking spaces occupied in parking lot $j$ at iteration $m$, and $C_{j}$ is the capacity of parking lot $j$. 


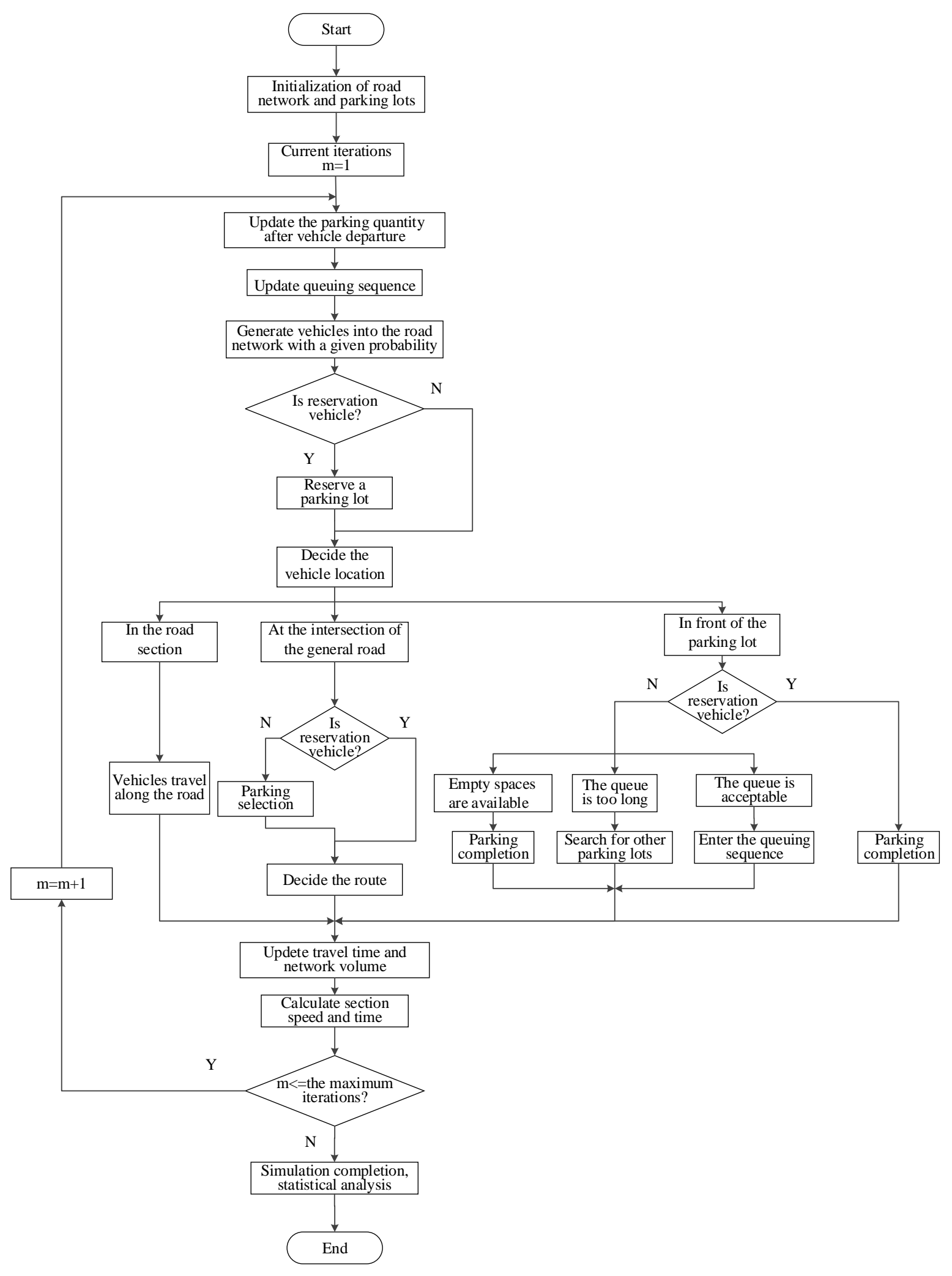

Figure 1. Flowchart of the agent-based simulation model.

For the first two pricing policies (different parking lots constantly charge the same price and different parking lots constantly charge different prices), a change in SOP will not influence parking prices. For the last pricing policy (different parking lots charge different prices during peak periods), the corresponding parking and reservation fees will change when the SOP is higher than the large threshold. 


\section{Vehicle Agent Generation}

Vehicle agents are randomly generated in the road network in accordance with OD demand. Reserved vehicles reserve a target parking space upon generation. Non-reserved vehicles will select the target parking lots at intersections, and the selection process will be illustrated. The cost of reserved users consists of vehicle travel time, walking distance, reservation fee, and parking fee. Therefore, the negative utility of parking lot reservation is calculated as follows:

$$
U_{b p c}^{r}(m)=a_{1} \cdot t_{b p}(m)+a_{2} \cdot d_{p d}+a_{3} \cdot t_{p}^{\text {search }}+a_{5} \cdot f_{r}(m)+a_{6} \cdot f_{p}(m)+a_{7} \cdot \xi,
$$

where $U_{b p c}^{r}(m)$ represents the disutility of vehicle $c$ reserving parking lot $p$ from intersection $b$ at iteration $m, t_{b p}(m)$ is the shortest travel time from the current intersection $b$ to parking lot $p$ at iteration $m$ obtained using Dijkstra's algorithm [25], $d_{p d}$ is the walking distance from parking lot $p$ to destination $d, t_{p}^{\text {search }}$ is the estimated cruising time [26], $f_{r}(m)$ and $f_{p}(m)$ are the reservation and parking fees at iteration $m$, respectively, $\xi$ is a random term, and $a_{1}, a_{2}, a_{3}, a_{5}, a_{6}$, and $a_{7}$ are all negative coefficients.

A reservation vehicle will choose its parking lot on the basis of utility maximization principle. A reservation vehicle will become a non-reservation vehicle when no empty parking space is found near the destination.

\section{Vehicle Decision Making}

The location of vehicles in the road network can be placed in threefold, namely, in a general road section, at an intersection, and in front of a parking lot. Vehicles in general road sections need not make decisions.

- Decision making at intersections

At every intersection, reservation vehicles find the shortest paths to their reserved parking lots in accordance with the network traffic conditions. Non-reservation vehicles will first choose their parking lots and then select the paths to the parking lots. The factors influencing parking lot choice include travel time, walking distance, estimated cruising time, estimated queuing time, and parking fee. The negative utility can be obtained as follows:

$$
U_{b p c}^{n r}(m)=a_{1} \cdot t_{b p}(m)+a_{2} \cdot d_{p d}+a_{3} \cdot t_{p}^{\text {search }}+a_{4} \cdot t_{p}^{w a i t}(m)+a_{6} \cdot f_{p}(m)+a_{7} \cdot \xi,
$$

where $U_{b p c}^{n r}(m)$ represents the negative utility of nonreservation vehicle $c$ choosing parking lot $p$ from intersection $b$ at iteration $m$, twait is the estimated queuing time at parking lot $p$ and iteration $m$ [27], and $a_{4}$ is a negative coefficient.

Non-reservation vehicles will choose parking lots that maximize their utilities on the basis of utility maximization principle. Then, they find the shortest paths to their target parking lots similar to reservation vehicles.

- Decision making in front of parking lots

A reservation vehicle experiences no waiting when it reaches the target parking lot. A non-reservation vehicle completes parking without waiting when the target parking lot has an available parking space, enters the queue when the parking lot does not have an empty space and the queue length is tolerable, and re-enters the road network and heads toward another parking lot when the parking lot does not have an empty space and the queue length is intolerable.

\section{Updating Vehicle Locations and Network Traffic Conditions}

Vehicles drive along their predetermined paths, and their locations are updated at every time step. The traffic volume of each road section can be determined when the locations of all vehicles are 
known. The travel speed and travel time of each road section can then be obtained by applying the BPR function.

\section{Case Study}

The core area of Wulin CBD, Hangzhou, China is applied as a case study to analyze and assess the different parking pricing strategies. The reason for choosing Wulin CBD is because there are serious parking problems in the area, including parking demand far exceeding supply and uneven parking space distribution. The parking pricing strategy in this area currently adopts the first parking pricing strategy. Parking managers are aware of the need to change the parking pricing strategy, but it is difficult to know how to change and access the strategy. Therefore, analysis and assessments for different parking pricing strategies in this typical area through simulation are of great significance. The simulation road network contains 4 origins, 4 destinations, 18 intersections, 9 off-street parking lots, and 54 road sections, as shown in Figure 2.

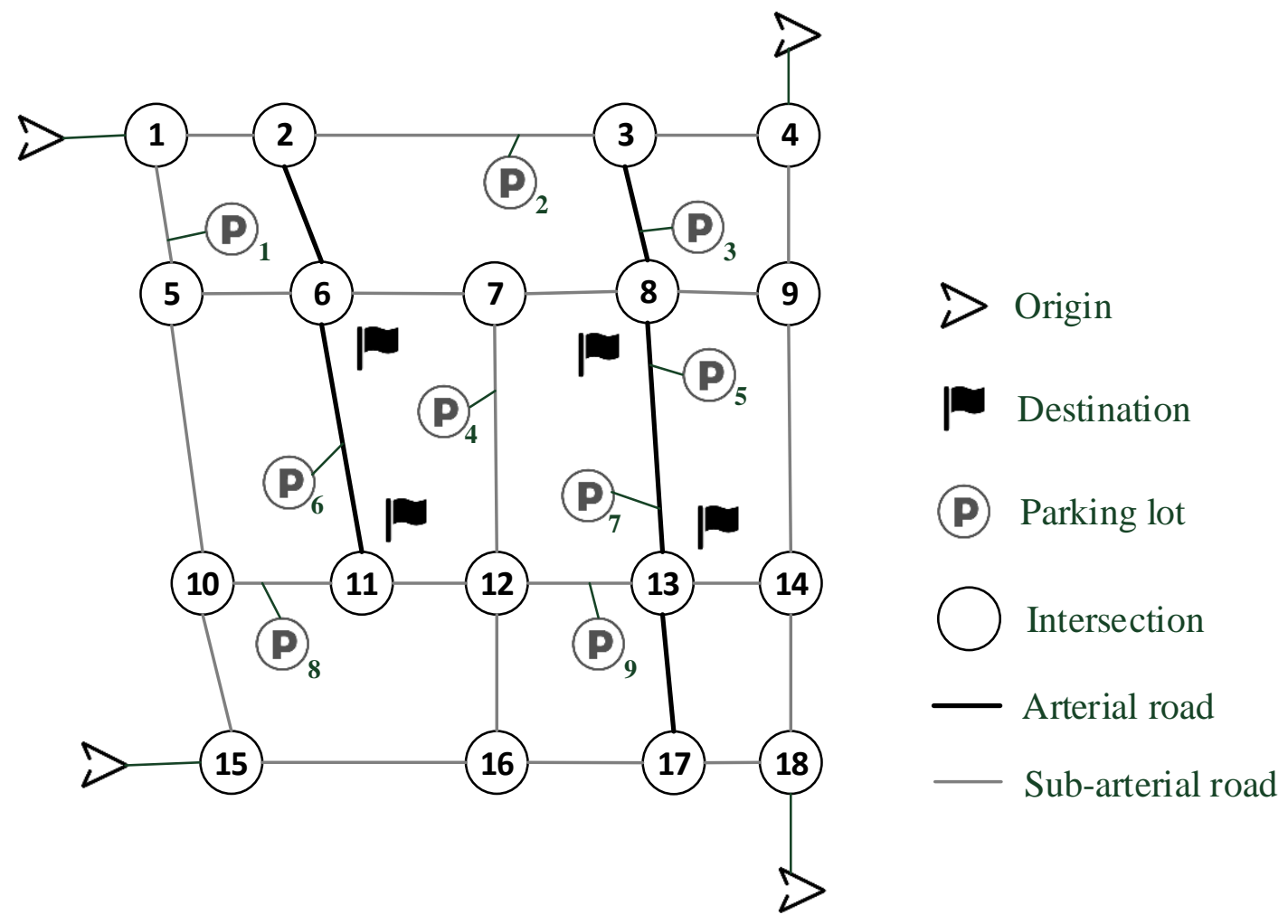

Figure 2. Simplified simulation road network.

The simulation horizon is $2 \mathrm{~h}$ or $7200 \mathrm{~s}$, and simulation time step $\Delta t$ is $1 \mathrm{~s}$. The total OD demand is 2600 vehicles. The parking capacities are 180, 300, 160, 310, 190, 210, 230, 240, and 280 vehicles for good parking lots, Thus, the total parking space can accommodate 2100 vehicles. The expected vehicle departure rate is 600 vehicles per hour. BPR function parameters $\alpha_{p}$ and $\beta_{p}$ are obtained from the study of Lam [28]. For arterial roads, $\alpha_{p}=1$, and $\beta_{p}=5$. For sub-arterial roads, $\alpha_{p}=0.8$, and $\beta_{p}=4$.

The agent-based simulation model can provide various performance measures. We construct a comprehensive benefit to evaluate different mechanisms, which can be expressed as follows:

$$
Z=100 /\left(\alpha \cdot \gamma_{1} \cdot \bar{f}+(1-\alpha) * \gamma_{2} * F\right)
$$

where $\alpha$ is a weight coefficient, $\gamma_{1}$ and $\gamma_{2}$ are equilibrium coefficients to unify the scale of parameters, $\bar{f}$ is the average cost of drivers who complete parking, and $F$ is the failure rate (the number of cruising 
vehicles/the total number of vehicles). We set $\alpha=0.5, \gamma_{1}=1$, and $\gamma_{2}=250$. Large $Z$ is preferred by drivers.

The initialization of the simulation environment is basically completed. We can obtain the corresponding results by changing the pricing strategy.

\subsection{Different Parking Lots Constantly Charge the Same Price (Strategy 1)}

The reservation fee is set to $2 ¥(\mathrm{RMB}$, Chinese currency), and the parking fee is set to $3 ¥ / \mathrm{h}$ for all parking lots. Five simulation runs were performed to alleviate the influence of random errors. The simulation results are summarized as Table 1.

Table 1. Simulation results of strategy 1.

\begin{tabular}{ccccccc}
\hline $\begin{array}{c}\text { Number of } \\
\text { Vehicles }\end{array}$ & $\begin{array}{c}\text { Number of } \\
\text { Cruising Vehicles }\end{array}$ & $\begin{array}{c}\text { Average Travel } \\
\text { Time (s) }\end{array}$ & $\begin{array}{c}\text { Average Travel } \\
\text { Distance }(\mathbf{m})\end{array}$ & $\begin{array}{c}\text { Average } \\
\text { Cost }(¥)\end{array}$ & Failure Rate & $\begin{array}{c}\text { Comprehensive } \\
\text { Benefit }\end{array}$ \\
\hline 2606 & 530 & 728 & 1954 & 3.0 & $20.3 \%$ & 3.7 \\
\hline
\end{tabular}

The changes in the SOP of each parking lot are recorded in the simulation. Figure 3 presents the evolution of SOPs for the nine parking lots. Some parking lots are saturated for a long time. For example, the SOP of parking lot 5 reaches $100 \%$ at $25 \mathrm{~min}$ from the start of simulation.

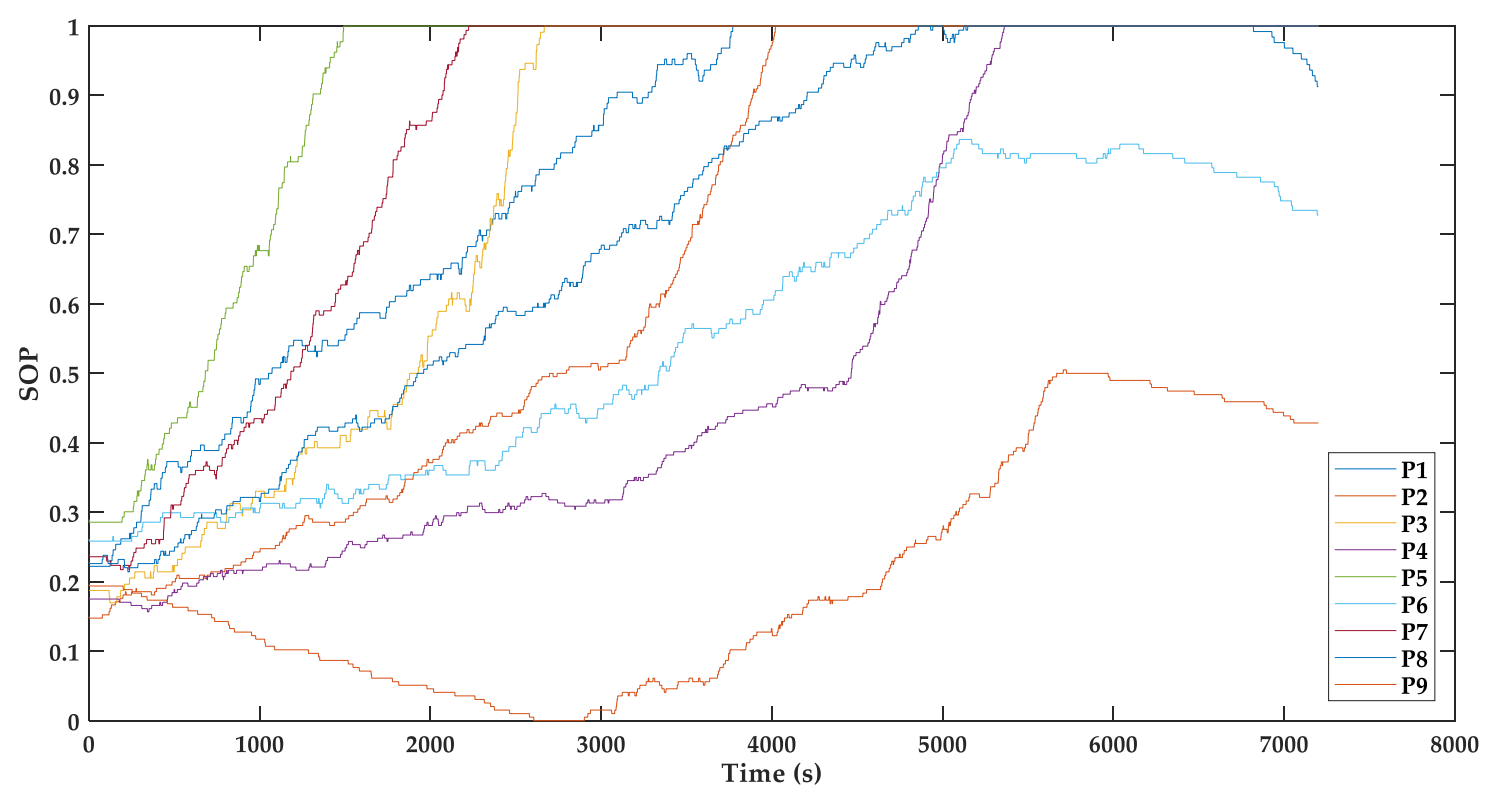

Figure 3. Evaluation of space occupancy percentage (SOPs) under strategy 1.

\subsection{Different Parking Lots Constantly Charge Different Prices (Strategy 2)}

The changes in reservation and parking fees can influence the vehicles' parking choices. The impact of each parking lot's fee settings on the system performance is dependent. The optimal reservation and parking fees of the nine parking lots need to be simultaneously determined. The computation burden of grid search for 18 variables (9 reservation fees and 9 parking fees) is extremely large. Hence, we used a heuristic algorithm called genetic algorithm.

Genetic algorithm is an evolutionary method based on the phenomena of heredity, mutation, natural selection, and hybridization. Evolution starts from the population of completely random individuals. In each generation, the fitness of the entire population (i.e., the optimization goal) is evaluated, multiple individuals are selected on the basis of specific standards, and new species are generated through natural selection and mutation. The optimal solution is found. 
We set the generations of pricing in the genetic algorithm to 75 and the population size to 40 . The optimized fee settings are shown in Table 2.

Table 2. Optimized reservation and parking fees for strategy 2.

\begin{tabular}{cccccccccc}
\hline Parking Lot & $\mathbf{1}$ & $\mathbf{2}$ & $\mathbf{3}$ & $\mathbf{4}$ & $\mathbf{5}$ & $\mathbf{6}$ & $\mathbf{7}$ & $\mathbf{8}$ & $\mathbf{9}$ \\
\hline Reservation fee $(¥)$ & 4.5 & 5.9 & 14.7 & 21.8 & 13.1 & 11.7 & 7.9 & 3.3 & 3.7 \\
\hline Parking fee (¥) & 4.8 & 11.5 & 19.9 & 1.8 & 43.8 & 1.0 & 38.6 & 3.1 & 29.6 \\
\hline
\end{tabular}

The simulation results are presented in Table 3. Compared with strategy 1 , the failure rate of strategy 2 decreases from $20.3 \%$ to $5.5 \%$, indicating a drop of $73 \%$. The average travel time and travel distance also significantly decrease. The average cost increases and reaches $16.5 ¥$ because parking lots are allowed to raise parking prices. The overall comprehensive benefit improves by $78 \%$. So, in terms of the comprehensive benefit, strategy 2 works better than strategy 1 .

Table 3. Simulation results of strategy 2.

\begin{tabular}{ccccccc}
\hline $\begin{array}{c}\text { Number of } \\
\text { Vehicles }\end{array}$ & $\begin{array}{c}\text { Number of } \\
\text { Cruising Vehicles }\end{array}$ & $\begin{array}{c}\text { Average Travel } \\
\text { Time (s) }\end{array}$ & $\begin{array}{c}\text { Average Travel } \\
\text { Distance }(\mathbf{m})\end{array}$ & $\begin{array}{c}\text { Average } \\
\text { Cost (¥) }\end{array}$ & Failure Rate & $\begin{array}{c}\text { Comprehensive } \\
\text { Benefit }\end{array}$ \\
\hline 2602 & 144 & 663 & 1606 & 16.5 & $5.5 \%$ & 6.6 \\
\hline
\end{tabular}

The changes in the SOP of each parking lot are recorded in the simulation. Figure 4 presents the evolution of SOPs of the nine parking lots. The SOPs of popular parking lots reach $100 \%$ later compared with those in strategy 1 . The parking resources are sufficiently used, except parking lot 9.

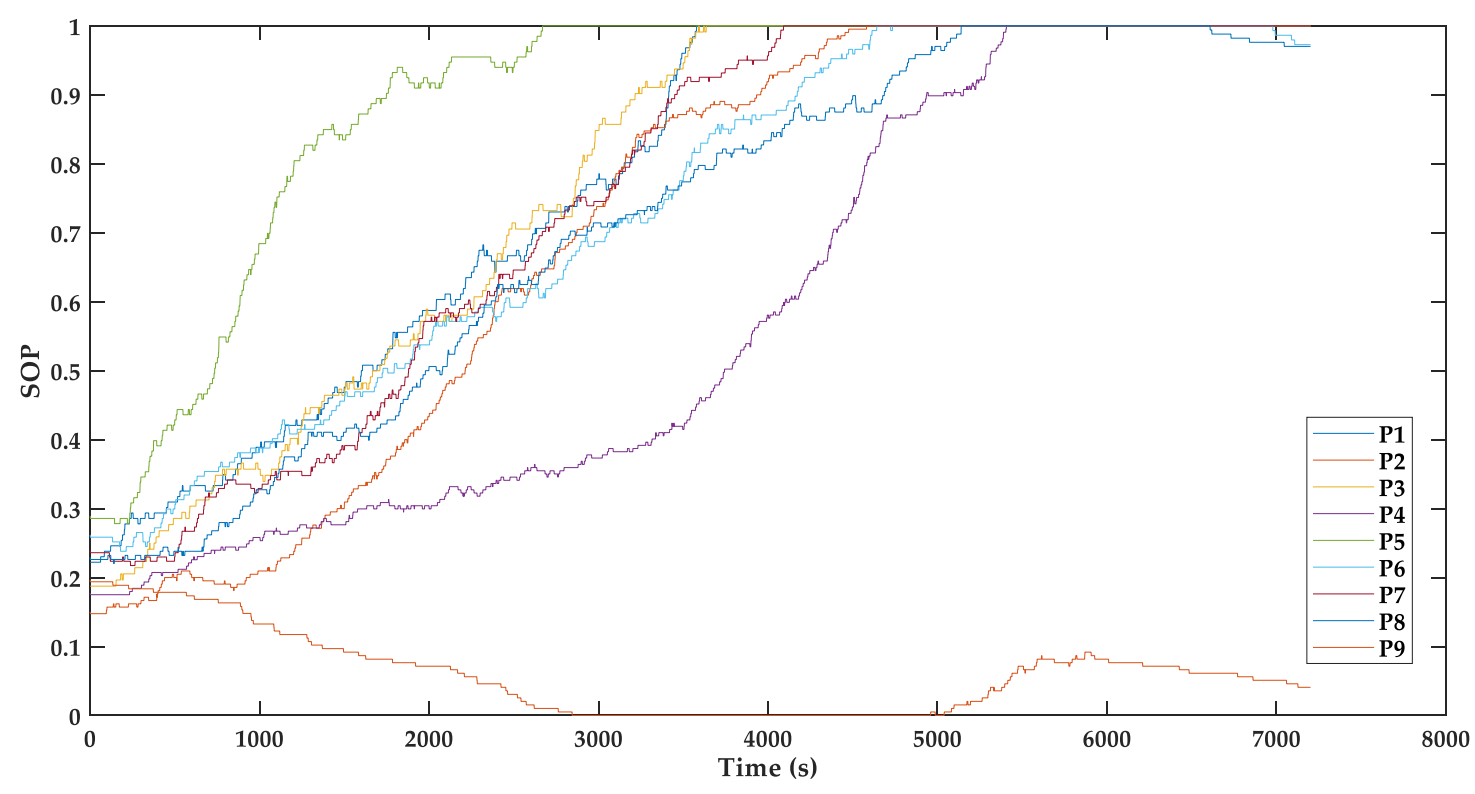

Figure 4. Evaluation of SOPs under strategy 2.

\subsection{Different Parking Lots Charge Different Prices During Peak Periods (Strategy 3)}

Although strategy 2 effectively reduces the failure rate and produces a larger comprehensive benefit, its average cost is higher than strategy 1. Changing users' parking choices is unnecessary when parking resources are ample, and we set two SOP thresholds, namely, large and small SOPs. The reservation and parking fees of a parking lot will increase when its SOP exceeds the large threshold. The reservation and parking fees will return to regular levels when the SOP drops below the small threshold. 
We set the two SOP thresholds to 0.9 and 0.8 and reapply the genetic algorithm (generations to 75 , population size to 40 ) to optimize the comprehensive benefit. The optimized fee settings during peak periods are shown in Table 4.

Table 4. Optimized reservation and parking fees during peak periods for strategy 3.

\begin{tabular}{cccccccccc}
\hline Parking Lot & $\mathbf{1}$ & $\mathbf{2}$ & $\mathbf{3}$ & $\mathbf{4}$ & $\mathbf{5}$ & $\mathbf{6}$ & $\mathbf{7}$ & $\mathbf{8}$ & $\mathbf{9}$ \\
\hline Reservation fee $(¥)$ & 28.2 & 6.3 & 4.0 & 1.9 & 27.1 & 22.4 & 16.0 & 14.9 & 29.1 \\
\hline Parking fee $(¥)$ & 6.6 & 13.6 & 42.7 & 3.5 & 37.2 & 22.4 & 46.8 & 6.2 & 14.2 \\
\hline
\end{tabular}

The performance measures are presented in Table 5. Compared with strategy 2, strategy 3 exhibits insignificant changes in the average travel time, average travel distance, and failure rate whereas the average cost reduces to $8.6 ¥(48 \%$ drop). The comprehensive benefit increases and reaches 8.2 . Strategy 3 accordingly works better than strategy 2 and strategy 1 .

Table 5. Simulation results of strategy 3.

\begin{tabular}{ccccccc}
\hline $\begin{array}{c}\text { Number of } \\
\text { Vehicles }\end{array}$ & $\begin{array}{c}\text { Number of } \\
\text { Cruising Vehicles }\end{array}$ & $\begin{array}{c}\text { Average Travel } \\
\text { Time (s) }\end{array}$ & $\begin{array}{c}\text { Average Travel } \\
\text { Distance }(\mathrm{m})\end{array}$ & $\begin{array}{c}\text { Average } \\
\text { Cost }(¥)\end{array}$ & Failure Rate & $\begin{array}{c}\text { Comprehensive } \\
\text { Benefit }\end{array}$ \\
\hline 2614 & 165 & 655 & 1589 & 8.6 & $6.3 \%$ & 8.2 \\
\hline
\end{tabular}

The changes in the SOP of each parking lot are recorded in the simulation. Figure 5 presents the evolution of SOPs. In the early stage, the SOPs of popular parking lots increase as fast as those under strategy 1 because reservation and parking fees remain unchanged when the SOPs are below the small threshold. Users can choose parking lots close to their destinations. Thus, the average travel time and distance are smaller than those under strategy 2. The SOPs of several parking lots decrease when they exceed 0.9 because of increased prices during peak periods. Under strategy 3 , the utilization of parking resources is balanced, that is, the SOP of parking lot 9 is larger than that under strategy 2.

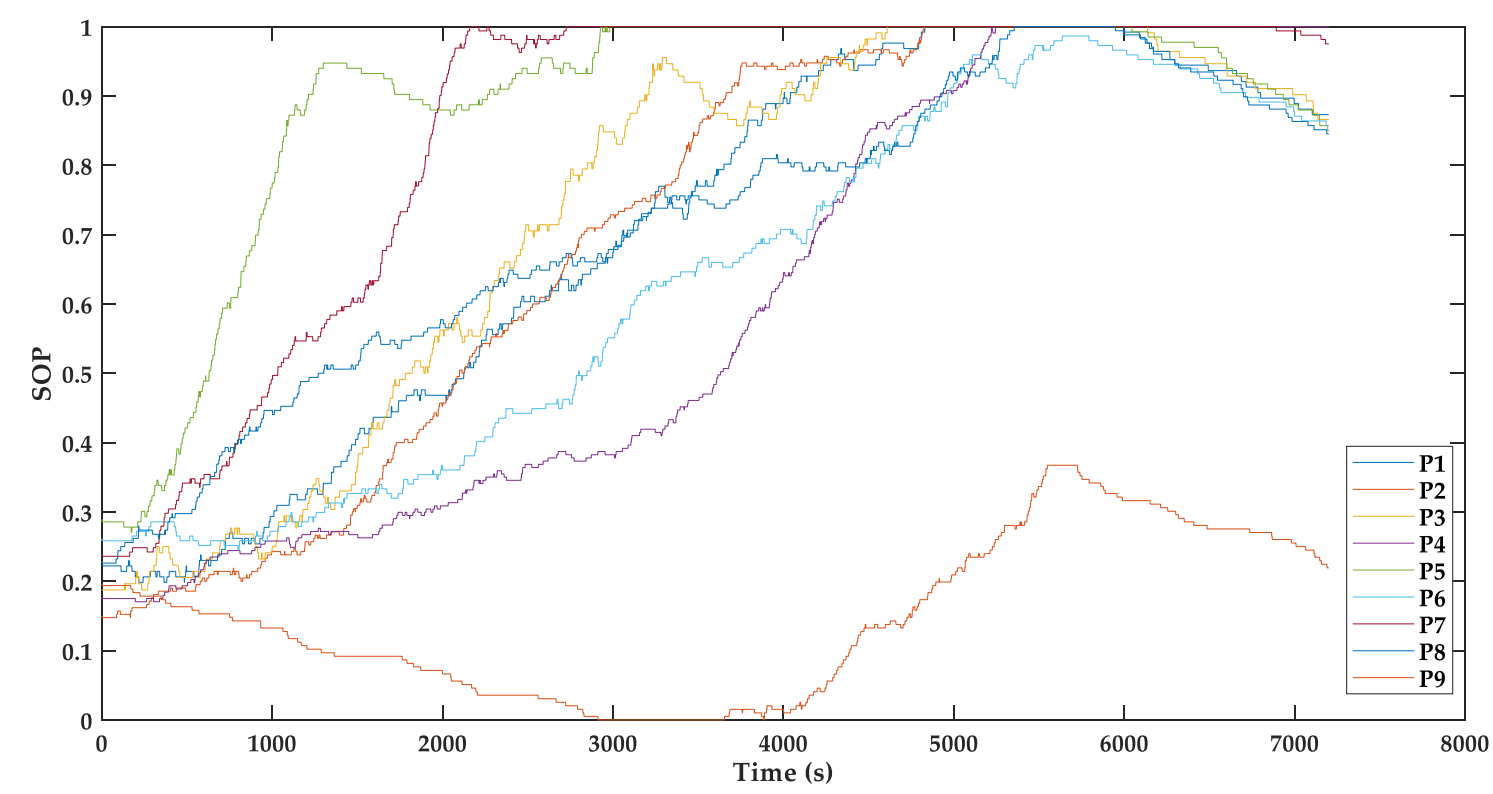

Figure 5. Evaluation of SOPs under strategy 3.

\section{Discussion}

Figure 6 intuitively shows the comprehensive benefits of the three parking pricing strategies. The comprehensive benefit is related to the average cost and failure rate. The failure rates under strategies 
2 and 3 are similar and smaller than that under strategy 1 . The average cost under strategy 1 is the lowest, whereas that under strategy 2 is the highest. Strategy 3 achieves the largest comprehensive benefit, whereas strategy 1 is the worst.

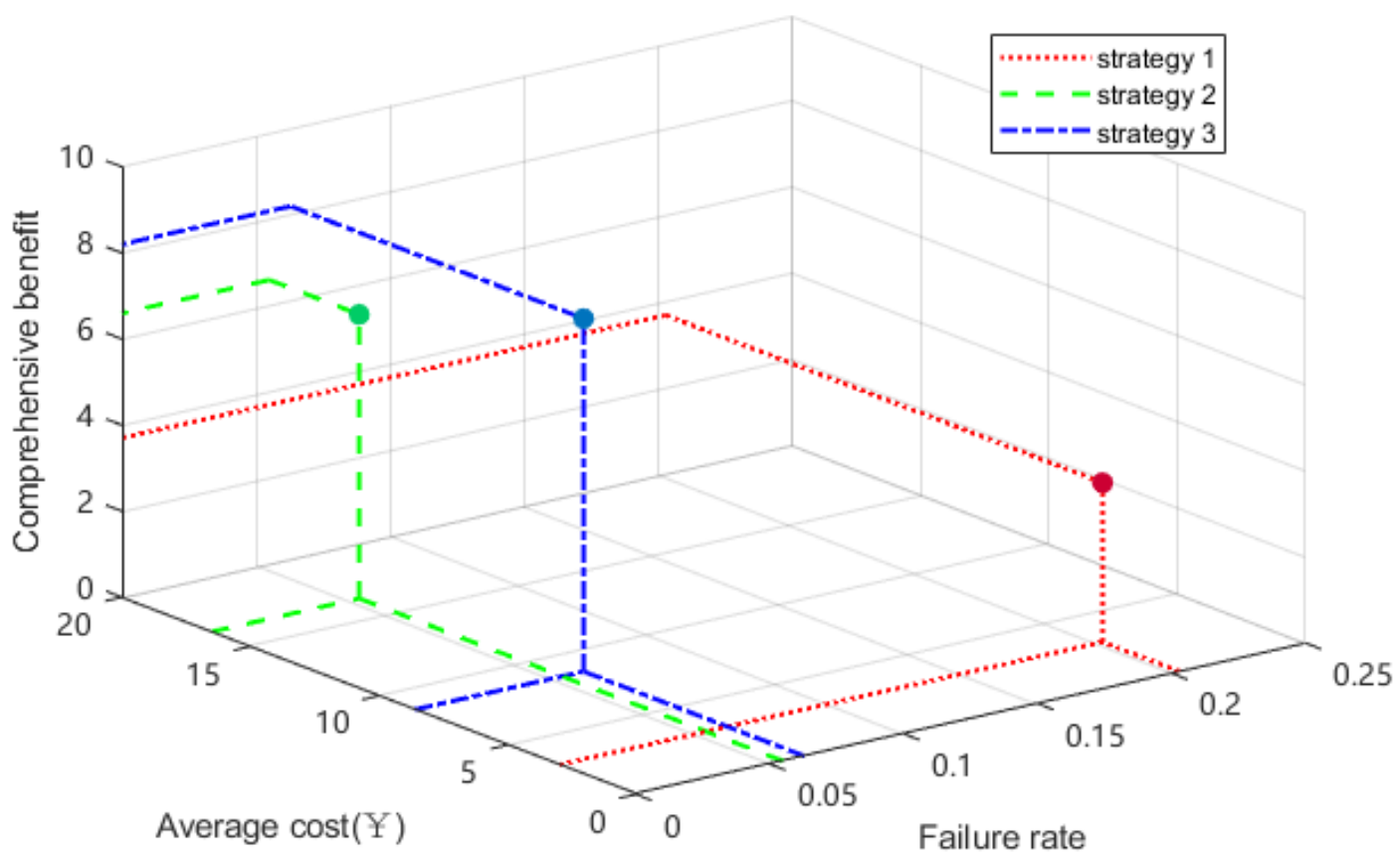

Figure 6. Comprehensive benefits of the three parking-pricing strategies.

Strategy 3 performs the best on the basis of the defined comprehensive benefit. the price of parking resource is low when it is rich, whereas its differential pricing can affect drivers' parking choice to avoid parking failure when it is limited. Different performance measures may be considered from different perspectives. For example, the focus of the prior literature is diverse, which includes parking location utilization, public acceptance, and revenue. This model can help government agencies or researchers in evaluating their parking strategy and finding its appropriate pricing when the optimization objective is determined.

\section{Concluding Remarks}

The two currently used parking pricing strategies in China combined with an optimized parking pricing strategy are proposed. This optimized strategy is proposed for different charging prices by comprehensively considering different locations, time periods, and methods. We present an agent-based simulation system to evaluate these strategies. The agent-based system works well and it can actually bring detailed simulation results of each agent. The conclusions are summarized as follows:

1. Varying parking prices can disperse drivers to unpopular parking lots, which makes parking resource used more effectively;

2. Varying parking prices in strategies 2 and 3 leads to improvements in main traffic indicators including average travel time, average travel distance, and failure rate;

3. Charging different prices only during peak periods performs the best among the three parking pricing strategies on the basis of comprehensive benefits.

Compared with the prior research, we take both consideration of pricing and time periods. By agent-based simulation, we also quantify the strategies which is helpful for policy-making. Following the work presented in this paper, we recognize some areas that may be explored in future research. 
1. Different pricing strategies have different impacts on users' willingness to drive. Cost-sensitive users may choose other travel modes, such as public transport. Thus, parking pricing with consideration of elastic parking demand can be investigated;

2. The SOP thresholds and the determination of peak periods for different parking lots can be analyzed;

3. Dynamic pricing strategies other than charging differently only during peak periods may work better and can be investigated;

4. The parking pricing strategy and parking lot locations may be simultaneously optimized to improve the overall system performance.

Author Contributions: The authors confirm contribution to the paper as follows: conceptualization, Z.M.; formal analysis, C.F.; methodology, C.F., Z.M. and L.Z.; investigation, L.K.; resources, J.C. All authors reviewed the results and approved the final version of the manuscript.

Funding: This research was funded by the Zhejiang Provincial Natural Science Foundation of China [No.LY19E080016], the National Natural Science Foundation of China [No.50908205,71971059] and National Key R\&D Program of China [No.2019YFB1600300].

Acknowledgments: In this section you can acknowledge any support given which is not covered by the author contribution or funding sections. This may include administrative and technical support, or donations in kind (e.g., materials used for experiments).

Conflicts of Interest: The authors declare no conflict of interest.

\section{References}

1. Kotb, A.O.; Shen, Y.; Huang, Y. Smart parking guidance, monitoring and reservations: A review. IEEE Intell. Transp. Syst. Mag. 2017, 9, 6-16. [CrossRef]

2. $\quad$ Rogers, J.; Emerine, D.; Haas, P.; Jackson, D.; Kauffmann, P.; Rybeck, R.; Westrom, R. Estimating Parking Utilization in Multifamily Residential Buildings in Washington, DC. Transp. Res. Rec. 2016, 2568, 72-82. [CrossRef]

3. Wilson, R.W. Estimating the travel and parking demand effects of employer-paid parking. Reg. Sci. Urban Econ. 1992, 22, 133-145. [CrossRef]

4. Tsamboulas, D.A. Parking fare thresholds: a policy tool. Transp. Policy 2001, 8, 115-124. [CrossRef]

5. Kelly, J.A.; Clinch, J.P. Influence of varied parking tariffs on parking occupancy levels by trip purpose. Transp. Policy 2006, 13, 487-495. [CrossRef]

6. Bonsall, P.; Young, W. Is there a case for replacing parking charges by road user charges? Transp. Policy 2010, 17, 323-334. [CrossRef]

7. Jansson, J.O. Road pricing and parking policy. Res. Transp. Econ. 2010, 29, 346-353. [CrossRef]

8. Caicedo, F. Charging parking by the minute: What to expect from this parking pricing policy? Transp. Policy 2012, 19, 63-68. [CrossRef]

9. Zhang, R.; Zhu, L. Curbside parking pricing in a city centre using a threshold. Transp. Policy 2016, 52, 16-27. [CrossRef]

10. Dale, S.; Frost, M.; Ison, S.; Quddus, M.; Warren, P. Evaluating the impact of a workplace parking levy on local traffic congestion: The case of Nottingham UK. Transp. Policy 2017, 59, 153-164. [CrossRef]

11. Gao, G.; Sun, H.; Wu, J.; Liu, X.; Chen, W. Park-and-ride service design under a price-based tradable credits scheme in a linear monocentric city. Transp. Policy 2018, 68, 1-12. [CrossRef]

12. Cai, Y.; Chen, J.; Zhang, C.; Wang, B. A Parking Space Allocation Method to Make a Shared Parking Strategy for Appertaining Parking Lots of Public Buildings. Sustainability 2018, 11, 120. [CrossRef]

13. Hao, J.; Chen, J.; Chen, Q. Floating Charge Method Based on Shared Parking. Sustainability 2019, 11, 72. [CrossRef]

14. Rodier, C.J.; Shaheen, S.A.; Eaken, A.M. Transit-based smart parking in the San Francisco Bay Area, California: assessment of user demand and behavioral effects. Transp. Res. Rec. 2005, 1927, 167-173. [CrossRef]

15. Kurauchi, F.; Iida, Y. Simulation Analysis on the Evaluation of Parking Reservation System. East. Asia Soc. Transp. Serv.-Jpn. Work. Pap. Ser. 2008, 8, 2. 
16. Tasseron, G.; Martens, K. Urban parking space reservation through bottom-up information provision: An agent-based analysis. Comput. Environ. Urban Syst. 2017, 64, 30-41. [CrossRef]

17. Mei, Z.; Feng, C.; Ding, W.; Zhang, L.; Wang, D. Better lucky than rich? Comparative analysis of parking reservation and parking charge. Transp. Policy 2019, 75, 47-56. [CrossRef]

18. Mei, Z.; Zhang, W.; Zhang, L.; Wang, D. Optimization of reservation parking space configurations in city centers through an agent-based simulation. Simul. Model. Pract. Theory 2020, 99, 102020. [CrossRef]

19. Caliskan, M.; Barthels, A.; Scheuermann, B.; Mauve, M. Predicting parking lot occupancy in vehicular ad hoc networks. In Proceedings of the 2007 IEEE 65th Vehicular Technology Conference-VTC2007-Spring, Dublin, Ireland, 22-25 April 2007; pp. 277-281.

20. Klappenecker, A.; Lee, H.; Welch, J.L. Finding available parking spaces made easy. Ad Hoc Netw. 2014, 12, 243-249. [CrossRef]

21. Chou, S.Y.; Lin, S.W.; Li, C.C. Dynamic parking negotiation and guidance using an agent-based platform. Expert Syst. Appl. 2008, 35, 805-817. [CrossRef]

22. Sun, D.J.; Ni, X.Y.; Zhang, L.H. A discriminated release strategy for parking variable message sign display problem using agent-based simulation. IEEE Trans. Intell. Transp. Syst. 2015, 17, 38-47. [CrossRef]

23. Boudali, I.; Ouada, M.B. Smart Parking Reservation System Based on Distributed Multicriteria Approach. Appl. Artif. Intell. 2017, 31, 518-537. [CrossRef]

24. Wang, R.; Yuan, Q. Parking practices and policies under rapid motorization: The case of China. Transp. Policy 2013, 30, 109-116. [CrossRef]

25. Dijkstra, E.W. A note on two problems in connexion with graphs. Numer. Math. 1959, 1, 269-271. [CrossRef]

26. Tsai, M.T.; Chu, C.P. Evaluating parking reservation policy in urban areas: An environmental perspective. In Eastern Asia Society for Transportation Studies, The 9th International Conference of Eastern Asia Society for Transportation Studies, 2011; Eastern Asia Society for Transportation Studies: Jeju, Korea, 2011; Volume 8, p. 272.

27. Mei, Z. Optimization Method of On-Street Parking Facilities in Urban. Ph.D. Thesis, Southeast University, Nanjing, China, 2006.

28. Lam, W.H.; Li, Z.-C.; Huang, H.-J.; Wong, S.C. Modeling time-dependent travel choice problems in road networks with multiple user classes and multiple parking facilities. Transp. Res. Part B Methodol. 2006, 40, 368-395. [CrossRef] 